\title{
César Vallejo, Hombre y Poeta
}

\section{- I -}

En la presente charla, no puedo intentar un estudio amplio y detenido de lo que es, de lo que representa la poesía de Vallejo: la nocine no me bastaría para llevar a cabo tal empresa. Por lo tanto, me limitaré a recordar unos cuantos momentos de la biografía del poeta, relacionando luego dichos momentos con las etapas sucesivas de una producción poética que trataré de coracterizar en cada uno de los li bros publicados.

No voy a remontarme hasta Santiago de Chuco y aquellos días lejanos en que el pequeño César Abraham 'Abrahancito, como lo llama. ban los familiares) "chivateaba" por los caminos que llevaban a la chacra de sus padres, o se arrebujaba "en las tibias colchas de vicuña" cuando su madre lo despertabào"con cantora Tyelinda cólera"'. Tomaré al poeia por primera vez en Trujillo. Corre el año 1916; desde 1913, Vallejo está matriculado en la Facultad de Letras de la Universidad de La Libertad; ya ha presentado su tesis de bachillerato sobre el tema: "El Romanticismo en la Poesía Castellana", donde justifica de antemano toda renovación de las formas artísticas que esté basada en la sinceridad. del artista.

A fines de diciembre del año anterior, el estudiante ha regresado a Santiago y se ha apeado "en el poyo de la casa", de esa misma ca sa de la que, terminadas las vacaciones, lo alejan nuevamente sus pasos; ahora mientras en el hogar serrano se ha quebrado algo y reina la soledad "sin bulla, sin noticias, sin verde, sin niñez", el joven, también solitario, cruza una vez más, rumbo a Trujillo, las amargas y silenziosas alturas de los Andes, cuya visión nos trasmitirá más tarde en el cuento"'Fabla Salvaje"; recordemos aquí que en esos años, no tan lejanos, a los que nos estamos refiriendo la mayor parte de las carreteras que hoy surcan el Perú no existían todavía; eran tiempos aquellos en que, para ir de Santiago de Chuco a Trujillo, se requería cuatro 
días de viaje a caballo: en las mañanas grises, esas mañanas "preñaclas de electricidad y de hórrido presagio que palpitan en todo tiempo sobre las tristes y rocallosas jalcas peruanas", los encuentros eran raros. apenas de vez en cuando uno que oiro arriero, "saboreando el romance de su coca"; sin embargo luego se multip!icaban conforme iba bajando el camino y humanizándose el paisaje; por fin se llegaba a la hacienda de Menocucho, donde se abandonaban las cabalgaduras para tomar el tren costeño hasta la cercana capital del norte.

En Trujillo esperan a Vallejo sus amigos de la Bohemia, en cuyo círculo va creciendo el prestigio del santiaguino que aparece ya como el abanderado de la juventud estudiantil y revolucionaria. Pero la rəbeldía de Vallejo no es nada caprichosa, nada superficial, nada pasajera, como suele serio en muchos jóvenes; no apunta hacia afuera, hacia la resistencia del medio circundante, sino que se fundamenta en una verdad interior, honda y angustiada. Ciro Alegría, quien tuvo al autor de los Heraldos Negros por prezeptor en el colegio de San Juan de Trujillo, nos resurne en la forma siguiente el choque emocional que experimento al verlo por primera vez: "Magro, cetrino, hierático, me pareció un árbol deshojado. Su traje era oscuro, como su piel os. cura... de todo su ser fluía una gran tristeza. Nunca he visto un hombre que pareciera tan triste..." En torno a Vallejo entre tanto han nacido las polémicas iniciales que suscita toda obra nueva que rompa lanzas contra la chatura $\mathrm{y}$ la insipidez inteleetualade la sociedad inmediata. Tanto en LimaJ come Enc Trujillo, da crítica oficial reacciona en forma por lo menos extraña.

Al comentar un soneto que iba a ser recolectado en los Heraldos Negros, una de lás personalidades más representativas del mundo de las Letras, no vacila en escribir, en la revista Variedades: "Nos remite Ud. un soneto titulado: El Poeta a su amada, que en verdad lo acredita a Ud. para el acordeón o la ocarina más que para la poesía"..."

Vallejo por supuesto no se deja desalentar por semejantes necedades y por semejantes amenazas; en un ambiente que todos los con temporáneos nos han pintado con los colores modernistas.y simbolistas, él está creando una obra propia y que pronto se ha de revelar como esencialmente original no sólo frente a la producción de sus enemigos o detractores, sino también de sus amigos y partidarios En 1918, Vallejo llega a Lima. Allí encuentra a Valdelomar, quien después de conocerlo en un café le espeta una de aquellas frases intencionalmente desconcertantes que solía usar: "Ahora ya puede Ud. decir en Trujillo que ha estrechado la mano de Abraham Valdelomar". Pero detrás del 
gesto espectacular se daba sitio en el Conde de Lemos para la ponderación exacla y perspicaz del interlocutor; al poco tiempo de embromar a Valiejo, Valdelomar lo saludaba como un poeta en la más noble acepción de la palabra, y a los H. N. como "'un hermoso y raro libro de versos" del cual pensaba ocuparse luego en detalle.

\section{- II -}

Los H. N., ya que los hemos nombrado, salen a luz esie mismo año de 1918. Es preciso considerar el libro desde el doble punto de vista de la tradición y de la novedad. Uds. saben perfectamente que cási nunca (y bien podemos suprimir el casi) la expresión original de un artista no debe confundirse con su expresión primitiva; la originalidàd no es una disposición que se de en el principio, es más bien el término de un a veces largo y complicado proceso de liberación y de conquista. Ya en la vida diaria nuestras acciones más corrientes e inmediatas son quizás las menos personales; en la mayoría de nuestras conductas acluamos como astuaría cualquiera otra persona nacida en el mismo ambiente que nosotros; si queremos mostrarnos sinceros, tenemos que despojar toda esa hojarasca social que ros oculta nuestra esencia más profunda. El poeta, cuando empieza a escribir, se encuentra obligado a realizar algo semejante: dispone de un vocabulario, de unas formas, de unas fórmulas también, Levocabulario, formas, fórmulas que le preexisien yr de los quie le les difícil enoun comienzo escapar para alcanzar su modo propio de expresarse. Los H. N. señalan el conflisto entre la presión externa del arte entonces vigente y la pujanza interior de una personalidad irreductible a los moldes y escuelas que pronto haibía de seguir un derrotero desconcertante inclusive para sus primeros admiradores.

Por lo tanto las huellas de la poesía modernista en sus distintas manifestaciones (simbolismo, pre-expresionismo, impresionismo, etc.), son palmarias a lo largo del primer libro de Vallejo. En Rubén Darío, el poeta santiaguino adivinaba un espíritu fraternal el poemă "Retablo" 'o atestigua), pero de quien más sufría la influencia era de Herrera y Reissig, el vate solitaric de la Torre de los Panoramas en Montevideo; omnipotente en las primeras composiciones esa influencia se revela aún en los poemas más originales del libro por uno que otro detalle de expresión: en "Heces" por ejemplo, un verso entero: "en la abrupta arruga de mi dolor" es la transposición quizás inconsciente de un verso de Herrera: "la arruga de mi alma se hizo más honda". 
Lo interesante, al estudiar los H. N., es determinar cómo en los coemas más nutridos de influencias, una rupiura impensada del ritmo, una exageración barroca en las imágenes, un giro familiar, etc., pueden revelar una personalidad que rebasa los cauces tradicionales de la poe. sía, - mientras que, en las composiciones más inéditas rarás veces desaparecen por completo, si bien se atenúan, los rasgos culturales y literarios.

Lo que a primera vista integra a Vallejo en una corriente más general que se inicia en los años de la primera guerra mundial, es el que rechaze inmediatamente y de una vez por todas en su poesía la preocupación por la forma bella y el lenguaje pulcro; pero, a! acercarse a las cosas de uso cotidiano y al transmutarlas en materia poética, Vallejo no se deja llevar del prosaismo descriptivo y anecdótico de la poesía intimista, sino que obedece a una exigencia apremiante por la cual queda transformada al menos la anécdota: efectivamente es por el contacto con las cosas cotidianas como él experimenta la angustia del abandono y el cloior abrumedor de tiempo.

Desde entonces, la poesía, 'balbuceada e inexperta, se mantiene al nivel exacto en que se da la sensación de las amenazas oscuras y deseos elementales que el autor afirma y repite sin lograr individualizar ni superarlos: el "Yo no sé" que siempre vuelve revela una incapacidad fundamental para definir aquellas fuerzas primitivas, anteriores a la vida del espíritu; y en ese universo fo intelectualizado, cuando asoma li conciencia alboreante delcuerpocpersonal ellaelogra únicamente acrecentar todavía la angustia al introducir ese sentimiento irracional de culpa que resulta patente por ejemplo en el poema "El Pan nuestro". De allí que la poesía que examinamos acuda cada vez menos al prestigio de las imágenes, que se desarroile fuera de las normas lógicas, más cerca del lenguaje hablado que del lenguaje escrito (eso digo en su vocabulario pero sobre todo en su' estructura: cabría señalar aquí todas las falsas conclusiones, las interrupziones, repeticiones, etc., traduciendo la persistencia del sentimiento que no logra expresarse cabalmente).

$Y$ es entonces cuando, el idioma mostrándose insuficiente, el poeta empieza a utilizar las palabras en acepciones raras, y luego a crear nuevas palabras o a unir las ya existentes de un modo gramaticalmente inusitado (" $\tan$ suave, $\tan$ ala, $\tan$ salida, $\tan$ amor", etc....) ○ a agotar un vocablo determinado dándole vueltas y más vueltas ("saboreando un sabor ya sin sabor", etc.). Descubrimos en los ejemplos precedentes los elementos de una utilización nueva del lenguaje que se verificará de lleno en la época de Trilce. La confesión primitiva de renun- 
cia que señalaba el "Yo no sé" nos lleva finalmente a una renovación del lenguaje que parece ser también liberación.

A la base de todo ese esuferzo de expresión, encontramos el sentimiento particular que el poeta tiene del tiempo: en la poesía de Valle;o, la evocación de una escena remota tiende a resolverse por la supresión de la lejanía y la superposición de dos realidades en el presenie donde tanto la ausencia como el pasado son experimentados como falta, defecto o privación, - siendo la tarde, el tiempo predilecto de la muerte, la que llega a ocupar la vida entera: "En todas las tardes de esta vida", leemos en efecto en "Agape" y en Deshora: "pues de la vida en la perenne tarde". El poeta, incapaz de asumir de modo abstracto su experiencia no puede, desde el exceso de su abandono, sino formular una aspiración contra los límites que lo rodean, y es en el centro mismo de la sensación presente donde surge el grito triunfal de "Ene. reéida" por el cual se recupera el tiempo total, proyectando el pasado hacia un porvenir liberado: la "mañana eterna" de Eneréida responde a la 'perenne tarde' de Deshora. Ahora bien ese momento de liberación es de todas maneras excepcional y no puede hacer que olvidemos la expresión angustiada que traduce de ordinario el sentimiento del tiempo: en la renovación del lenguaje intentada por Vallejo las palabras del lenguaje temporal ozupan desde el principio un papel predominante: Herrera y Reissig puede haber inspirado todavía versos como éste, calificado por Parra del Riego de "peciosista": "un nido azul de alondras que mueren al nacer pero ent versos como: ' $y$ hoy he muerto que pozo en esta tarde'"go l'puesidel la vidaven da perenne tarde, nació muy poco pero mucho muere", tan solo subsiste la necesidad de transmitir la experiencia agónica y lógicamente paradójica de una vida con más carga de muerte que de vida, experiencia que será mucho más tarde ahondada y profundizada en $\mathrm{P}$. $\mathrm{H}$.

La unidad del primer libro de Vallejo consiste pues, en la tonalidad afestiva ya indicada en el poema incial: es la zozobra de un niñc desamparado (siendo el hambre la manifestación menos transitoria de ese desamparo), la zozobra de un niño que se siente, antes de tiempo, huérfano (notemos aquí que el papel futuro de la madre en Trilce y P. H. lo encontramos ya anunciado en los H. N.: por ejemplo en una expresión del poema "Las Piedras": "madre nuestra" sustituída a la expresión evangélica "Padre nuestro"). Esa misma congoja esencial a la que nos referimos no logra justificarse y quizás redimirse sino por una ternura apasionada que envuelve hasta las piedras. Los H. N., se salvan de la retórica, peligro mayor para la poesía americana, precisd- 
mente por permanecer fieles a una oscura inquietud cuya elaboración poética queda muy reducida. Puede ocurrir entonces que el lenguje de Vallejo confunda sus pasos con el del hombre de las alturas en constante relación con las misteriosas fuerzas cósmicas, - pero lo que : 1 pceta debe a un ambiente terrestre determinado, cualquiera de nosotrc.3. adentrándose en su propia niñez, puede enconirarlo a su vaz en acquellas zonas afectivas de la angustia y la ternura que pre-existen a todo proceso y desarrollo intelectual.

Al considerar los H. N.,, acabamos de subrayar ante todo rasgos poéticos que precisarán las obras posteriores del mismo autor. Es tiempo que volvamos a encontrar las andanzas humanas de Vallejc, Lo hemos dejado en Lima en 1918. El medio literario limeño, agit:do por Valdelomar cuyo talento se aviene finalmente a reconocer el director de "Variedades", Clemente Palma, se abre a valores nuevos, de los cuales los más espectaculares en poesía parecen ser los arequipeños Albrto Hidalgo y Alberto Guillén. Las resistencias o el silencio cubren sin embargo para Vallejo la voz escasa de los admiradores. En "Escalas melografiadas", el mismo poeta alude, a través de varias páginas de prosa, a la vida que entonces llevaba con sus amigos de la capital. En "Cera", que se desarrolla en el ambiente de los fumaderos del Bariio Chino, celebra su "Bohemia" de aquel tiempo en qa que apunta, coms dice, "el círculo de su carabliberlad de hombrevalos" aceras de realidad hasta por tres sienes de imposible'.

Entre tanto, en Agosto de 1918, la madre de Vallejo ha muerto en Santiago y con ella quizás se ha roto el último vínculo que impedía al hijo menor realizar este viaje a Francia, con el que venía soñando desde hacía algún tiempo. Antes de embarcarse, el poeta quiere llevarse el postrero recuerdo de la provincia donde nació; en 1920, cruza por última vez las tierras altas del Perú con sus hombres "de mirada vegetal y lapídea expresión", esas tierras que "sacuden de un calofrío de inmensa orfandad". Llega Val. a Santiago de Chuco para celebrar con los suyos las fiestas del Patrón Santiago y es entonces cuando ocurren, después de una semana de diversiones y borracheras, incidentes sangrientos que culminan en la noche del 25 con el incendio de la mayor casa comercial de la ciudad. No tengo tiempo para resaltar lo ocurrido, según se desprende de los legajos del proceso subsecuente, que se conservan en Trujillo. Lo cierto es que los acontecimientos alu- 
didos se explican por la confusa rivalidad de dos bandos provinciales que, tiempo atrás, venían disputándose la prepotencia; Val. presenció únicamente el desenlace de dicha rivalidad y, siendo su familia relacionada con uno de los bandos opuestos, se encontró complicado en el auto judicial que a poco se inició en la capital del departamento de La Libertad. Pero mientras los demás acusados, aprovechando las condiciones propias del medio, se salvaron ocultándose un tiempo, Val., por mera casualidad, caía preso en Noviembre de 1920; permaneció en la cárcel hasta febrero del año siguiente, cuando las intervenciones de sus amigos y admiradores lograron que lo pusieran en libertad condiciona!.

La huella de la prisión es preponderante en la vida y la obra de V.: En Poemas Humanos escribirá todavía: "El momento más grave de mi vida fué mi prisión en una cárcel del Perú". Al escritor de "Eszalas melografiadas", la celda le aparece desde el principio como el signo negativo del hogar, el signo del abandono y de la angustia. La ternura del artista hacia todos los hombres se vuelve más honda y definitiva: en el cuento "Liberación", dice del jefe de los talleres tipográficos del Panóptico: "Es un penitenciado, un bueno, como lo son todos los delincuentes del mundo", y en "Muro noroeste" concluye: "La justicia... no se ejerce, no puede ejercerse por los hombres ni a los ojos de los hombres. Nadie es delincuente nunca. O todos somos delincuentes siempre".

De vuelta a Lima V. Mermina Trilce y prepara el gran viaje de París. Podemos evócar "esos umomentos silenciosos" que transcurren hasta el 17 de Junio de 1923, fecha en que el poeta se embarca para Fran. cia. Podemos scbre todo confrontar ese período de intensa y secreta responsabilidad con el estruendo ininimaginable que, por el mismo tiempo, acompaña a Chocano: efectivamente la prisión de Chocano contemporánea de la de V. nos revela la oposición fundamental no sólo de dos hombres sino más generalmente de dos temperamentos y quizás de dos generaciones; encarcelado en Guatemala después de derrocado su amigo el dictador Estrada Cabrera, el autor de "Alma América"" orquesta desde lejos su propaganda, comparándose con los grandes presos de la Historia: Cervantes, André Chénier o Oscar Wilde; su regreso al Perú, en Diciembre de 1921, es un triunfo: el reporter de Variedades, le saca fotos al lado de todos los monumentos públicos de Lima, y, en Noviembre de 1922, es la apoteósis de Chocano, auspiciada por el propio presidente Leguía: durante la ceremonia el mismo Chocano se iguala a Santa Rosa, y no falta quien lo salude en la forma si- 
quiente: "Padre Nuestro, que estás en el verso, glorificado sea tu nombre, ahora y sempre por los siglos de los sijylos. Amér?". Conlompl's Val. esa deificación de su antecesor? No lo sabemos. Lo que sí sa. bemes es que al poso tiempo abandona el Ferú, y nunca más volverá. Antes de embarcarse, bromeendo protéticamente, durante su último almueizo criollo, el que quince años más terde lóa a escribir "La rueda del hambriento" advertía a un tal Gálvez, su zompañero de viaje: "Acoztúmbrate a corner poco, que en París comeremos piedresitss".

\section{- IV -}

Trilce había salido a luz en 1922: el tílulo de la obra, neologismo numérico, se debe a una inspiración fortuita, - Val, habiendo un dín en la imprenta declarado súbitamente: "En tres soles se va vender, entonces se la va a poner Trilce" - pero ese título nos parsce sumemente acertado si lo relacionamos con un libro en que las palabras surgen sin ser anunciadas y el vocabulario numérico rompe a vivir de un modo inesperado.

Trilce nace en el momento en que la poesía de habla castellana, profundamente removida por el ultraismo, se encuentra en busca de nuevos cauces y nuevas fórmulas; todos los antiguos marcos estallan a un tiempo: el ritmo y la rima, "las cadenas de enganches sintácticos y las fómulas de equivalencias" "el tema narrativo y la efusión romántica". Pero la poesía de Trilce y la poesía española coelánea no tienen en común sino la voluntad extremadan de renovaeiónoy unas concordancias ante todo formales. V: no suprime deliberadamente la anécdota. (Un poema como Tr. 37: "He conocido a una pobre muchacha..." as un poema puramente efusivo y anecdótico, de valor muy relativo). Tampoco está ansioso por lograr esas series de imágenes y metáforas inéditas, aciertos líricos breves y atropellados que encontramos en la misma época en los poemas de Borge o de Diego. El carácter muchas veces abstracto del vocabulario de Tr. y el esfuerzo llevado hasta la desintegración, la "volatilización" - como escribía un amigo de V. — del lenguaje mismo, todo eso basta para señalar al libro un sitio solitario en la producción de los años 20-23.

Para Bergamin, en 1930, Tr. permanecía desconcertante; en la poesía americana de la década 1920-1930 sólo tiene igual importancia el libro sensiblemente posterior de Neruda: la primera "Residencia en la Tierra" (del tiempo en que Neruda era todavía poeta $y$ gran poeta); pero la "visión desintegrada" de Neruda, su experiencia de la destruc- 
Ción tempora! no dejan de ser acompañadas de todas las cosas del mun. do, de todas las materias del mundo en perpetua descomposición en las aguas del tiempo: la poesía de Neruda (me refiero siempre únicamente a Res. en la tiésin; es una poesía marcada por la presencia de los obisios, poesía compacta y sensual, que nos deja, a pesar de sus audacias sintácticas, la impresión de un desarrollo denso y continuo, de una caida lenta, oscura, inriensurable, cero siempre llena.

En Tr. por ei contrario no hay universo, no hay objetos sino aquellos que se iniroducen furtivamente a través del mundo cotidiano del horar o del amor; el contazto con el mundo se limita a unas sensaciones rápidas, percibidas en unos albores de consciencia por el choque emocional que determinan o por su resonancia interna que inpresicna hasta "el hueso". Los poemas son apenas poemas en el sentido tradicional de la palabra: algunos copian el habla naciente y obstinada de los niños, como 'Tr. 3, y más todavía Tr. 5l; casi todos organizan sus estrofas segúrn intuiciones separadas que indican los asaltos sucesivos del sentimiento o de la angustia yerbal. La imagen de tipo vanguardista, se puede decir gue no tiene papel alguno en el libro. En cambio, como lo señalábamos antes, la proporción de las palabras abs. traclas que a.canzan vida propia, vida separada, es considerable; entre ellas los números quizá səan las más carecterísticas.

La obsesión numériza está prof́undâmente ligada en la poesía de I'r. con la zozobra constånte del poetä; tengāmos en da mente un texio revelador de Escalas Melo. en que el autor después de declarar que la juslicia no puede ser "ejercida por los thombres nos presenta las razones de semejanie imposibilidad: "El hombre, dice, el hombre que ignora a qué tomperatura y con qué suficiencia acaba un algo y empieza otro algo; que ignora desde qué matiz el blanco ya es blanco y hastá dónde; que no sabe ni sabrá jamás qué hora empezzmos a vivir, qué hora empezamos a morir... el hombre que ignora a qué hora el 1 acaba de ser 1 , y empieza a ser 2 , cue hasta dentro de la exartitud matemática carece de la inconquistable plenitud de la sabiduría, etc..."

Como Uds. ven, la palabra que estructura el trozo precedente es "ignora". ¿Qué es lo que se ignora y cuya ignorancia llena al poeta de congoja? Es aquel paso vital permanente que sin cesar separa las cosas de las cosas y a nosotros mismos de nosotros mismos; estamos siempre en presencia de la amenaza fundamental que dominaba ya los H. N.: el transcurso de la vida a la muerle, de lo blanco a lo negro, del uno al dos señala una experiencia única en proceso de continua 
agonía. La idea fija de los límites (recordemos en los H. N. 'el paso meridiano de las lindes a las Lindes...") encuentra ahora su cabal significación. ¿Quién dirá cómo el 2 nace del 1, cómo el l mismo nace del 0 , de la nada? El 2 , el 1 , el 0 pierden su carácter meramente relativo y adquieren entonces un valor esencial de criâturas vivas.

Todo lo anteriormente mencionado da al libro ese tono "seco", "ardoroso" que tanto impresionaba a Bergamín. El lenguaje casi nuncti domina la emoción; trata más bien de surgir con ella en ráfagas que pronto se agotan, en relámpagos fulgurantes y breves; el lenguaje, no parece que el poeta lo recibiera como una herencia social aceptada de una vez por todas, sino que lo estuviera estructurando en el momento con todas las fallas, interrupciones, balbuceos que aquello encierra. La soledad frente al lenguaje es en realidad sólo un aspecto de la soledad frente a la vida. Cada vêz que el artista, después de intentar la imposible adecuación de las formas a lo intenso de la experiencia, se detiene para cobrar aliento, es la afirmación más despojada del dolor la que vuelve a aparecer; las palabras no se reunen $\in \mathrm{n}$ un cauce profundamente coherente sino en el momento de formular el sufrimiento primitivo. Siempre apegada al sentimiento inmediato, la expresión poética no logra proyectarse en una estructura estética conscientemente asumida; el idioma por lo tanto no logra tampoco realizarse de un mcdo definitivo.

Cuando Bergamihbescribia que una de las cualidades principales de la poesía de V. consistía en su arraigo idiomático castellano, quería decir que la poesía de $V$. es esencialmente intraducible; el hecho mis. mo de que $\mathrm{V}$. no se atenga a un idioma completamente cristalizado lo estrecha más todavía al idicma determinado - en este caso el castellano - que le proporciona sus materiales, en otros términos podremos decir que si pugna por forjarse en Tr. un idioma inaudito, este no se realiza sino a base del idioma particular que su esfuerzo tiende a descoyunta: - enriquecer, pero reconociendo por lo mismo su excelsa preeminencia. Muchas veces el lenguaje heredado parece para el poeta un lenguaje extraño, sin que quepa sin embargo la posibilidad de renunciar a él como fundamento del lenguaje propio que expresará el sentir interno en su mayor desnudez: lo mismo les ocurre a los niños que transforman, trastocan o reinventan las palabras que les son legadas por sus padres. El poeta, "huérfano del idioma", se confunde entonces con el ser primitivo rebelde a todos los auxilios que presenta la civilización, y expuesto a todos los golpes que se reciben desde afuera: la falta de organización lógica de los poemas traduce una experiencia sin 
perspectivas futuras, que no logra socializarse y utiliza las formas sociales del lenguaje como un recurso imposible de rechazar pero continuamente insuficiente y por lo tanto en peligro constante de renovación.

No puedo indicar todos los procadimientos idiomáticos a los que acude $V$. en sus poemas. Tan sólo rezordaré las relaciones nuevas entre ciertas palabras, las palabras que de ordinario traducen ideas - nociones abstracias y se excluyen unas a otras mientras que el autor de Tr. las hace suscitarse mutuamente, chocándose a veces, pero otras veces' sumándose o reconciliándose. También quiero señalar que casi iodos los poemas se terminan por seudo-conclusiones, cuyo Ejemplo más revelador quizá sea el último verso de Tr. 33: "Y basta!". Los poemas en realidad no avanzan hacia un fin; abortan incapaces de lib ertar la cbsesión nunca definida de ese "aquello" incógnito que vemos asomar sn mushos de ellos. El mismo poeta advierte en Tr. 53: "Véis lo que es sin poder ser negado, véis lo que tenemos que aguantar mal que nos pese".

Por todo lo dicho es evidente que la poesía corre varios riesgos contradictorios: a fuerza de permanecer presente a lo inmediatamente experimentado, pusde perderse en el seno del presente (Tr. 30 ó 43) - en un verbalismo relativamente arbitrario (Tr. 25), - por el chcque ardiente de los contrarios puede permitir que se insinúe nueva retórica, nuevo automatismo verbal 1 T5 nosiaparece en tonces como una constante exploración de los limites de la poesía y no nos extraña que V. haya confesado su miedo "de que todó se qe "fuere aermorir al fondo". Esa perspectiva, al mismo tiempo conquistadora y catastrófica, es la que garantiza al libro su fisonomía particular.

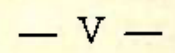

Sigamos ahora a V. hasta París. Nos falta tiempo desgraciadamente $y$ tenemos que concretarnos a unas breves anotaciones. Algunos han calificado los primeros meses que el poeta pasó en la capital francœsa, como unos meses de "bohemia"; el vocablo "bohemia" es sumamenle equívozo; de emplearlo habría que entenderlo en el sentido doloroso de miseria y de fatalidad que el mismo V. le dará en 1927, al szcribir: 'Yo sé de la bohemia, yo conozco su hueso amarillento, su marillo sin clavar"... En una carta de 1924, dirigida a un primo de Trujillo encontrábamos ya esta frase reveladora: "El peor presagio de una mala suerte es la inteligencia..." Luego sin embargo, V. ensaj- 
cha el círculo de sus relaciones humanas y pasa algunos años de relativa seguridad.

Desde 1925 hasta 1930, manda colaboraciones más o menos regujares a varias Ievisias americanas y sobre todo peruanas: es todo el París de la época, impregnado del rezuerdo de la lra. guerra mundial e impresionado por el hecho nuevo de la revolución rusa, el que aparece en los artículos de $V_{\text {; }}$ pero a través de las retereneias al ballet negro o a las películas de Chaplin, a Picasso o a Cocteau, a Poincaré o a Lindbergh, nos es dado seguir la evolución personal del escritor que va paulatinamente presisándose hasta los años 30 . Más fecundo quizá que ver el resultado de esa evolución, continuamente expuesto a revisión, sería tratar de determinar las a aíces profundas que la originan: la mayor contradicción que la guerra heya legado a la capital trancesa y al mundo, V. la encuentra en la convivencia en una misma sociedad del lujo desenfrenado y de ia creciente miseria; varias veces el contraste queda fijado para el en la imágen paralela de los pobres que se suicidan por las frías noches de inyieno y del opulento embajador de Stalin que lleva la vida elegante de París. A la larga, y sobre todo después de sus dos viajes a Rusia, V. lerminará de todas maneras por adherirse al comunismo y escribir Tungsteno de franci inspiración comunista.

Pero, ya que nos limitamos a hablar de la pcesía de V., nos cabe más bien preguntằnos et poraquéedōl eási comploto silencio poético que guarda el autor de Tr. durante muchos años. En 1926, publica en compañía de J. Lairea la revista "Favorableso "cue alcanza solamente 2 números, luego manda algunos poemas a revistas limeñas, pero muy pocos. Una carta de 1927, nos explica la repugnancia del artista: nasta ahora mi voto de conciencia estética ha sido "no publicar nada mientras no obedezca a una entrañable necesidad mía, tan entrañable como extraliteraria". Tr. señalaba unas fronteras ciue era difícil rebasar; parece que, en los años siguientes, el poela se haya dado cuenta al escribir de que seguía explotando una veta antiguamente descubierta en vez de obedecer un mandato verdadero de la sinceridad que para él constituia la condición indispensable del arte. Tal vez podamos oir como un eco personal en esas líneas críticas de 192,9: "Los indoamericanos somos ya por índole o por naturaleza telúrica precoces... A los 30 años hemos dado ya toda nuestra sangre en arte, en vida, en novelería..." Por lo tanto, en el caso de V., la permanencia de una sensibilidad humana excepcional, requeriría para manifestarse de nuevo febrilmente, en las cercanías de la muerte, el choque de acontecimien- 
tos exteriores igualmente excepcionales. En el período intermediario, la adhesión progresiva a una fórmula política determinada y la dedicación a tareas nuevas motivaría aún más la ocultación de la actividad propiamente poética.

El año 1930, marca un momento decisivo; V. que nunca ha simpatizado con los surrealistas escribe la "Autopsia del Surrealismo", artículo intencionalmente impersonal, que acumula contra el surrealismo todos los argumentos que hubieran podido reunir cualquier intelectual entonces afiliado al partido comunista. Este mismo año 1930, V., casado desde hace algunos meses con la que iba a convertirse en la compañera de los momentos más difíciles de su vida, tiene que desterrarse de Francia, perseguido por su actividad política. Su destino se decide. Expulsado de París, "París reine du monde", como reza uno de sus poemas, V. se acoge a España, donde había ido por primera vez en 1926 - y en aquella oportunidad había escrito: "Voy a mi tierra sin duda. Vuelvo a mi América Hispana reencarnada por el amor del verbo que salva las distancias, en el suelo castellano, siete veces clavado por los clavos de todas las aventuras coloniales". En España, el escritor peruano presencia el nacimiento de la República de cuya agonía será testigo unos años más tarde. De regreso a París, después de publicar Rusia 31, relación de los viajes precedentes a los países soviéticos, V. que se ha desprendido de sus amistades propiamente literarias y ha renunciado a toda actividad periodística en que no pudiera expresar llanamente sus ideas, inicia ese largo período de su existencia, al mismo tiem. po oscuro y trágicaméntedoloros6, cque habiande culminar en los meses también trágicos de la guerra civil española. Sobre la última enfermedad de $V$. otros han hablado y escrito. No quiero sino recordar una fecha, ia del 15 de abril de 1938, en que "muere en París" el que anteriormente había escrito: "César V. ha muerto, le pegaban todos, sin que él les haga nada'... D De las obras escritas en los años postreros casi todas - teatro y ensayos - quedan sin publicar. Debemos a la devoción póstuma de la Sra. Georgette de Vallejo, la publicación, e:1 1939, del libro Poemas Humanos que recoge al mismo tiempo los 15 poemas de "España, aparta de mí este cáliz"...".

$$
-\mathrm{VI}-
$$

Esa última particularidad nos permite advertir desde el principio una característica que separa a Val. de los demás poetas de la guerra española. Tomemos el caso de Neruda por ejemplo para quien la guerra 
es una sorpresa, un acontecimiento exterior que trastorna las razones íntimas; bajo la presión de los hechos, Neruda cambia radicalmente de manera: "El mundo ha cambiado, ciice, y mi poesía ha cambiado"; realiza por lo tanto una obra voluntaria y sienie la necesidad de justificar la modalidad nueva de su producción; uno de los poemas de "España en el corazón" se titula: "Explico algunas cosas"; de ahí que Neruda empisze pronto a seguir la pendiente fatal que !o llevará, después de un proceso lógico de envilecimiento, a renegar terminantemente de toda su poesía anterior. ¿Quién no ve en e! acto la diferencia fundamental con Val.? Los poemas "España aparta de mí este cáliz" quedan estrechamente unidos a los P. Humanos y éstos a su vez no implican una ruptura con los poemarios anieriores,, por más alejados que sean en el tiempo, sino más bien el ahondamiento de la experiencia primitiva que ha ganàdo en dramatismo y en urgencia. El mismo título "España aparta de mí este cáliz", indica que la existencia misma del poeta está en peligro en la guerra que se lleva a cabo en España. La presencia doble de la muerte - muerte individual y muerte colectiva - da una realidad impresionante al conjunto de los poemas.

Un lestor cualquiera que inicia la lectura de "P. Humanos", después de terminar la de Trilce, se da cuenta inmediatamente que la forma de las composiciones resulta en el libro póstumo mucho más amplia, menos coriada y agresiva, sin que eso signifique un retroceso hacia las leyes tradicionales de lä organización estrófica. Es un concepto nuevo de la unidad del poema el que ahora surge del movimiento propio de las vivencias interiores. UlDénodos modos, ala no usada ampli-tud del ritmo contribuye, al mismo tiempo que el contenido de los poemas, a crear la impresión de un pensar religioso, serio $\circ$ patético, que señalan títulos como Epístola a los transeuntes, Sermón sobre la muerte, etc. Las referencias bíblicas eran muchas en los H. N. Pero allí pertenecían al almacén común de los símbolos modernistas; en Pm. Hun. se trata por supuesto de una cosa distinta; se trata de nada menos que de encontrar la inspiración de las grandes voces bíblicas, integrándolas en una experiencia fundamentalmente original ya que, si el voca. bulario cristiano reaparece en la poesía de V., está siempre motivado por una necesidad libre de cualquier interpretación dogmática. Las palabras que por lo común designan lo Divino, cobran función propiamente humana. La Trinidad, de esta manera anda por las calles de París, - una mujer, un hombre y un niño -: "Yo tengo mucho gusto de ver así al Padre, al Hijo y al Espíritu Santo, cortados los emblemas e insignias de sus cargos". Esa humanización de lo Divino, 
arraiga en la conciencia, cada vez más lastimosa, que el poeta, como luego veremos, tiene de su propio cuerpo: "Estas son mis sagradas escrituras" leemos por ejemplo en la Epístola a los transeuntes, después de evocar los fundamentos corporales y animales de la persona en agonía.

Ahora bien, si el tono general de los Poemas se ha vuelto más dilatado, menos estridente, también el vocabulario se ha tranquilizado desde Trilce. Son pocas las creaciones de vocablos y series verbales como: "Loco de $\mathrm{mi}$, lobo de $\mathrm{mi}$, cordero de $\mathrm{mi}$, sensato. caballisimo de mí, revelan pronto el secreto de su formación; las acumulaciones de adjetivos o de adverbios, representan a su vez un papel relativamente fácil de justificar sino siempre de explicar del todo. La expresión retórica en la obra y la intuición patética en el alma y cuerpo del poeta corren parejas: no nos engañe la amplitud de forma que señalábamos anteriormente; la experiencia acongojada no logra, no puede en realidad lograr una expresión completamente adecuada. De ahí ciertos recursos idiomáticos que, en vísperas de la muerte, adquieren el peso que confiere la inminente catástrofa. Los adverbios de modo, por ejemplo, se imponen sistemáticamente para producir esa atmósfera de destrucción profética que caracteriza el libro; pesados y pausados al mismo tiempo, inspiradores de lentitud y gravedad, triunfan en el poema "Panieón" en el cual la presencia de la muerte se acentúa ante todo por el redoble múltiple de la terminación "mente" que aparece 20 veces en un total de 34 versos.

El poeta se entrega ar fos trocabilos lyi fenemos'entonces ese crecido número de asociaciones retóricas, tan particulares de la poesía de V. Llamo asociaciones retóricas (que no tienen nada que ver cuando están acertadas con la retórica), aquellas asociaciones que reunen palabras 0 expresiones que existían ya intelectualmente asociadas en la mente: He aquí dos o tres ejemplos: "El hombre es un mal nacido, mal vivo, mal moribundo, mal muerto", "Noches de sol, días de luna, ocasos de París", "Un pedazo de pan con gusanos hembras, gusanos machos y gusanos muertos", etc. Muchas veces esas series retóricas se reducen a dos vocablos que se entrechocan, destruyen o agregan, siendo los vocablos contradictorios, como la mencionábamos ya para $\mathrm{Tr}$. pero ahora en mayor cantidad, los que se presentan con más frecuencia. Algunos de ellos vuelven continuamente: izquierda y derecha, por ej., cuya alternativa queda a veces satisfactoriamente resuelta: "He trasladado ... el lado derecho de la vida al lado izquierdo", pero que casi siempre se mantiene irreductible e inquietante. Más aún se repiten los vo- 
cablos temporales. En los dos casos se trata da superar por el hechizo de las palabras las oposiciones, las contradicciones que abruman la vida.

Pongamos el caso de las reálidades temporales: el siglo o el año siempre para nosotros son más largos que el mes o la semana, la mañana siempre excluye la tarde, - el día, la noche, - el sábado, el dominzo, o el lunes. ¿No será posible evadirnos y por lo tanto salvarnos de la ruina que nos amenaza? "Hoy es domingo, y esto, tiene muchos siglos: de otra manera, sería quizá lunes", reza el poeta y a veces se atreve a afirmar la abolición de las contradicciones pero su triunfo está fecundado de amargura: "Me duele el pelo al columbrar los siglos semanales... paso la tarde en la mañana triste... etc.". En definitva, siempre se impone la contradicción esencial, a saber la constante interferencia de la vida y de la muerte, tanto en la aventura personal del poeta como en la lucha que se desarrolla mientras tanto en España. Cabría insistir por consiguiente sobre el aspecto verbal de la poesía de Valiejo, ya que revela la última instancia de su existencia agónica.

La ternura persiste como e! leitmovit de la esperanza y se vuelve cuanto más acuciosa que radica en una primaria impotencia; efectivamente cuando el poeta se ve obligado a advertir: "Cuídate España de tu propia España!' ets.' ' señala una imperfección fundamental. La ameraza de la muerte se cierne por todas partes. La incapacidad de ser feliz parece más definitiva todavía cada vez que, y son pocas las veces, encontramos presisamente la afirmación de la felicidad; el hombre trata de convencerse alcfuerzalideopalabras; tiene que advertirse así mismo: "No olvides en tu sueño de pensar que eres feliz". La experiencia de la muerte está en realidad incluída en la expəriencia de la vida; Val. experimenta el tiempo como una herida que se renueva de modo continuo en el presente: notemos por ej. que muchos poemas empiezan por "ahora", o por "hoy". Es en el instante en que nace la calidad profética del presente proyectado hacia el porvenir, mientras que la visión o mejor dicho la previsión del futuro a su vez se manifiesta en el presente con todas las características del pasado: "Me moriré en París... un día del cual ya tengo el recuerdo, etc.,". Las palabras "vivir, morir" asoman a través de los poemas, unidas precisamente en el momento de ahora. La afirmación de la vida lleva consigo paradójicamente la de la muerte: "Has soñado esta noche que vivías de nada y morías de todo..."; la vida es la única responsable de la muerte: "Cuando yo muera, de vida y no de tiempo...". La poesía a partir de cierto momento, se dedica exclusivamente a narrar el morir, el 
tanto morir de la vida: "¿Para sólo morir, tenemos que morir a cada instante?". Esa conciencia que parece interminable, y que desgraciadamente termina, del morir es lo más característico del último libro de Val. Para expresarla no hay necesidad de imágenes; al contrario; la intuición permanente primitiva, casi carnal; la vida se ha despojado de todos sus atributos; existe sola, confrontada con la muerte. El dolor reina, el dolor jóven, el dolor niño, el dolorazo", el dolor inmotivado $y$ sin embargo omnipresente.

La experiencia de la muerte no puede separarse de la experiencia del cuerpo: cuando V. habla de la muerte de los demás siempre lo hace a cuerpo presente, el cadáver está delante de nosotros, con sus antiguos objetos familiares: el zapato de Ernesto Zúñiga, el pantalón de Ramón Collar, la cuchara, muerta también, de Pedro Rojas; cuando V. vive su propia muerte, vive ante todo el tormento de su cuerpo; la pobreza está al principio de aquel tormento, - luego el hambre que da vida y simultáneamente dolor a los mismos alimentos: "estoy triste de ver el pan crucificado, al nabo ensangrentado, etc...."; el pan alimento esencial se vuelve evangelio; se nos habla de los 14 versículos del pan. La poesía se elabora a la altura de los deseos y sensaciones elementales; el cuerpo mismo se reduce a sus funciones primitivas. viscerales; la obsesión de la animalidad se revela constante: "tengo un miedo terrible de ser un animal... quiero escribir pero me sale espuma, etc...."; desprendida de todo, la vida animal en constante sufrimiento sigue siendo la vida Byl porl lo tanto deseable: "Me gustaría vivir siempre, así fuese de barriga.$"$ "Purante páginas enteras, el poeta prosigue el diálogo consigo mismo, con la parte más humilde de sí mismo, multiplicando en ella sus posibilidades de sufrir y morir. La forma general de los poemas que antes advertíamos, se explica por ese constante murmurar, a media voz, que se confunde a veces con una honda meditación, pero en general se concreta en unas variaciones sin descanso sobre el fondo permanente del dolor.

\section{VII}

Tiene muy poco sentido, creo, decir, como lo van repitiendo algunos, que $V$. es el más grande poeta mundial en lo que va de siglo. Fe lizmente no existen medidas para ponderar el genio y el talento. Por lo tanto otras poesías que la de $\mathrm{V}$. pueden imponerse a nosotros de modo tan inmediato, aunque diferente o divergente, sin que por ello V. pierda nada de su originalidad. Lo único importante para la crítica, 
frente a cualquier manifestación artística auténtica, ミs busar las caracieres propios que esa obra determinada azume en el ininenso panorami del espíritu humano. Lo demás, el benefitio que tal o sual persona pueza sacar de ella, ya no le corresponde a la crítica determinarlo; es asunto estrictamente individual. Pues bien, si es verdad que cada poeta tienẹ, según piensa Pedro Salinas, un tema vital que inspira cuanio enuncia o trata de enunciar, la poesía de $V$. apareco como soste. nida por aquél sentimiento de desamparo que no encuentra en el lengueje sino un recurso limitado e imperfecto. Poesis del tiempo suírido, pcesía que carece tanto de las cualidades intelectuales como de las cualidades "imaginantes" que otras puedan revelar - sus mecanismos verbales representan la réplica y trajucción necesaria de una angustia siempre por resolver. Conviene entonzes recordar - y asas serán mis últimas palabras - al lado de la intuición de P. H.: "La vida me ha dado ahora en toda mi muerte", la fórmula de Tr. que podriamos señalar como epígrafe a la obra poética de V.: "Orfandad de orfandades".

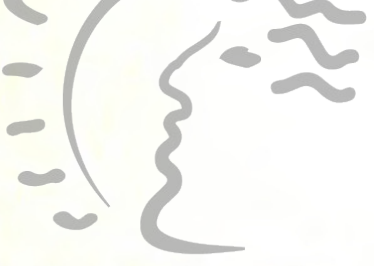

André Coyné.

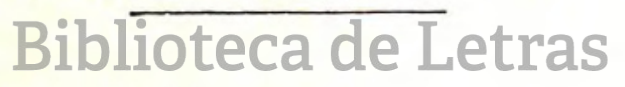
"Jorge Puccinelli Converso" 